\title{
Broadband Electromagnetic Coupled Octagonal Shaped Microstrip Patch Antenna for WiMax Application
}

\author{
Chandan Kumar Dubey \\ Asst. Prof. \\ Department of ECE \\ Poornima Group of Institutions, \\ Jaipur
}

\author{
Ranjeet Kumar \\ B. Tech., VIII Sem. \\ Department of ECE \\ Poornima Group of Institutions, \\ Jaipur
}

\author{
Vandana Kumari \\ B. Tech., VIII Sem. \\ Department of ECE \\ Poornima Group of Institutions, \\ Jaipur
}

\begin{abstract}
The aim of this research work is to enhance the bandwidth of an octagonal shaped microstrip patch antenna. For this purpose stacking concept has been used. Electromagnetic coupling is provided between the top and bottom patch. The dielectric substrate material of the antenna is glass epoxy FR4 having $\varepsilon_{\mathrm{r}}=4.4$ and loss tangent 0.025 . The performance of the final modified antenna is compared with that of a Rectangular Shaped Microstrip Patch Antenna (RSMPA) and Rhombus Shaped Microstrip Antenna (RSMA). The designed antenna has two resonant frequencies $5.29 \mathrm{GHz}$ and $5.49 \mathrm{GHz}$. So this antenna is applicable for the WiMax application. This electromagnetic coupled antenna offers much improved impedance bandwidth $22.08 \%$. This is approximately five times higher than that in a RSMPA antenna (Bandwidth $=4.43 \%$ ) having the same dimensions.
\end{abstract}

\section{General Terms}

Microstrip Patch Antenna, Gain, IE3D, VSWR

\section{Keywords}

Broadband, Stacked, Electromagnetically coupled, FR4 substrate, Bandwidth, Gain

\section{INTRODUCTION}

The microstrip patch antenna has found extensive applications in wireless communication systems owing to their advantages such as low profile, conformability, low fabrication cost and ease of integration with feed network [1]. Microstrip patch antennas come with a drawback of narrow bandwidth, but wireless communication applications require broad bandwidth and relatively high gain. The shape of antenna varies according to their use, gain and bandwidth they support [2]. The serious problem with patch antenna is their narrow bandwidth due to surface wave losses and large size of the patch. As a result, various techniques to enhance the bandwidth are proposed. Several techniques have been used to enhance the bandwidth by interpolating surface modification in patch configuration [3-6]. In the method of air gap filled substrates an air gap is added to the substrate to reduce the dielectric constant of the feeding substrate. This consequently increases the bandwidth [7]. Literature approves successful implementation of different broad banding techniques such as multilayer stacked patches. This consequently increases the bandwidth [8]. There have been a lot of developments in the field of antenna design in recent years. The researchers are focusing on Increasing gain and impedance, bandwidth and decreasing dimensions of microstrip antennas while keeping the antenna at low cost and easy to fabricate. But as far as bandwidth of these antennas is concerned, it is always a challenge to the researchers to significantly increase the bandwidth of Microstrip Patch Antenna. Different techniques have already been used for the bandwidth improvement such as using the substrate with low dielectric constant, using $\mathrm{H}$ shaped patches, stacked patches or by increasing the height of the substrate. [9]. One effective method to increase the bandwidth is to add a second patch in front of the basic one resulting in the so called dual patch microstrip antenna. The concept of stacking patches is realized through electromagnetic coupling form which gives bandwidth enhancement [10].

\section{ANTENNA GEOMETRY AND DESIGN}

In the designing process initially a single layer Rectangular Shaped Microstrip Patch Antenna (RSMPA) has been considered. Dimension for this antenna were taken as Length $\mathrm{L}=24 \mathrm{~mm}$ and Width $\mathrm{W}=30 \mathrm{~mm}$. Design and simulation process were carried out using IE3D simulation software 2007 version 12.30. The geometry of the RSMPA is depicted in figure 1 . The design parameters for all proposed microstrip antenna is depicted in Table-1.

Table 1: Design parameters for all proposed microstrip antenna

\begin{tabular}{|l|l|l|}
\hline $\begin{array}{l}\text { Sr. } \\
\text { no. }\end{array}$ & Parameters & $\begin{array}{l}\text { Design } \\
\text { consideration }\end{array}$ \\
\hline 1 & Patch dimension & $24 \mathrm{~mm} \times 30 \mathrm{~mm}$ \\
\hline 2 & Dielectric substrate (FR4) & 4.4 \\
\hline 3 & Substrate height & $1.6 \mathrm{~mm}$ \\
\hline 4 & Coaxial probe radius & $0.62 \mathrm{~mm}$ \\
\hline
\end{tabular}

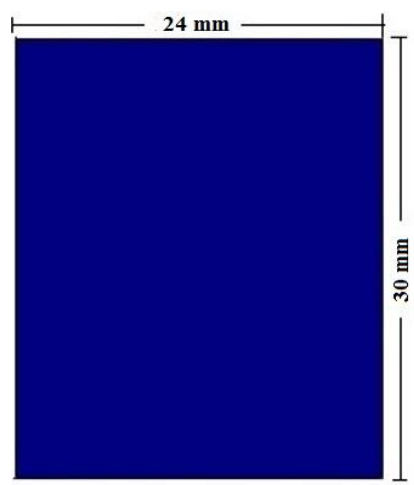

Figure 1: Geometry of Rectangular Shaped Microstrip Patch Antenna 


\section{SIMULATION AND RESULT}

\section{ANALYSIS}

The conventional rectangular shaped microstrip patch antenna is simulated first using IE3D software. This simulated reflection coefficient curve shows that the antenna is resonating at frequency $3.79 \mathrm{GHz}$ as shown in figure 2 .

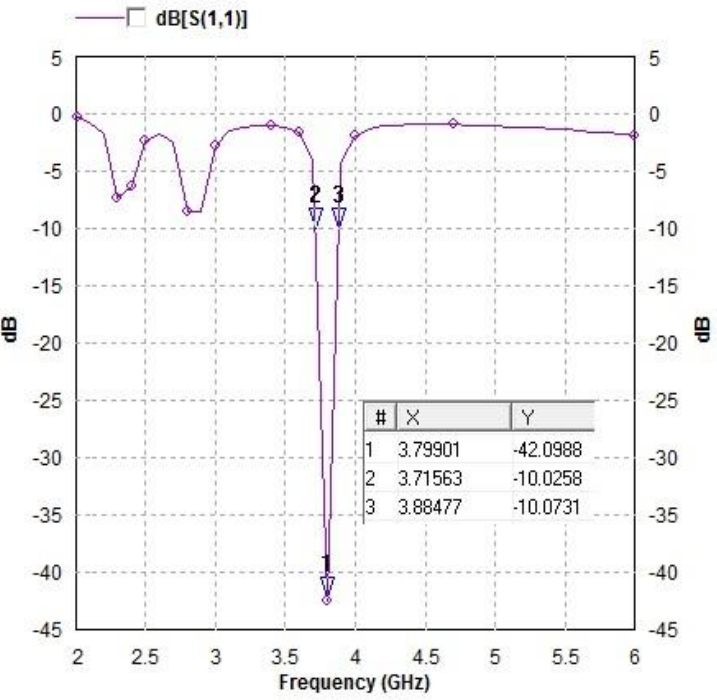

Figure 2: Variation of Reflection Coefficient v/s Resonant Frequencies

The value of impedance bandwidth is $4.43 \%$ as indicated in the figure 2 . The simulated input impedance of the antenna at resonance frequency $3.79 \mathrm{GHz}$ is $(51.42+\mathrm{j} 2.80) \mathrm{ohm}$ which is close to $50 \mathrm{ohm}$ impedance. Since the rectangular shaped microstrip patch antenna has low bandwidth, so to improve the performance of this antenna further modifications are required.

So in order to increase the bandwidth Rhombus Shaped Microstrip Antenna (RSMA) is designed by cutting four triangles from the corner sides of the rectangular shaped microstrip patch antenna. The structure of RSMA is shown in figure 3 .

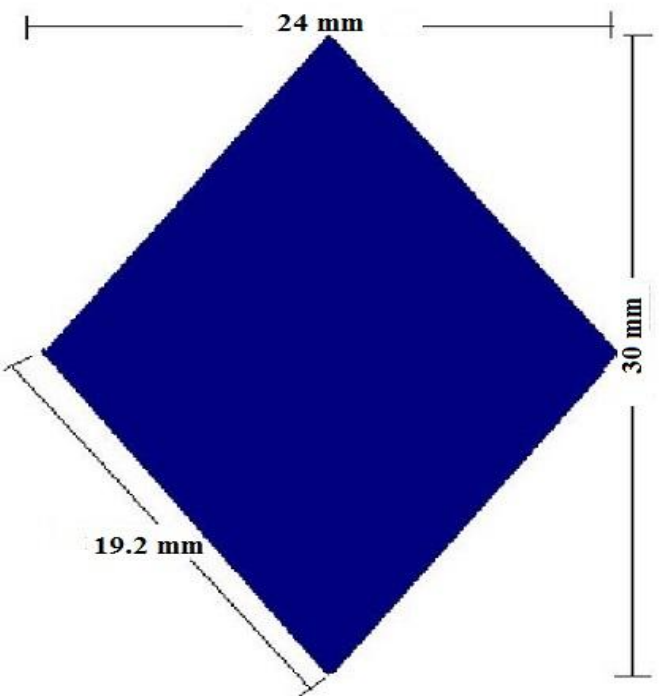

Figure 3: Structure of Rhombus Shaped Microstrip Patch Antenna (RSMPA)
Figure 4 shows the variation of reflection coefficient with frequency. It shows that the RSMA is resonating at $3.30 \mathrm{GHz}$ frequency. After modification of rectangular patch the obtained bandwidth is $4.53 \%$ as indicated in the figure 4 .

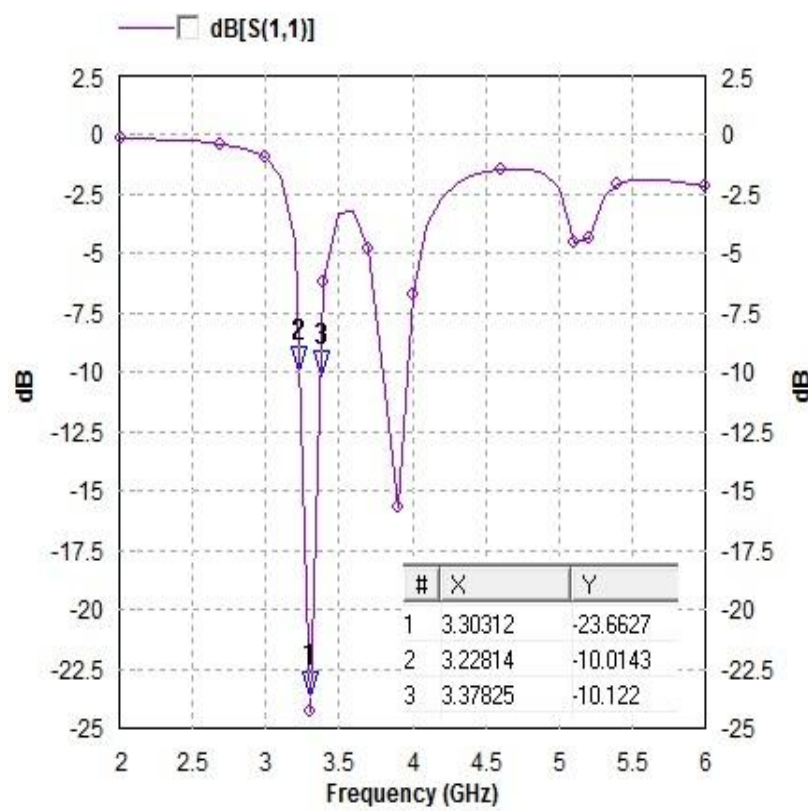

Figure 4: Variation of Reflection Coefficient v/s Resonance Frequency of RSMA

The simulated result shows that the input impedance at resonant frequency $3.30 \mathrm{GHz}$ is $(48.65-\mathrm{j} 3.29)$ ohm. Still precise bandwidth was not obtained. So in next step of designing process, some modification is done in the structure of RSMA to get wider bandwidth. Now Octagonal Shaped Microstrip Antenna with Rectangular Slot (OSMARS) is proposed. The dimension of rectangular slot is taken as $9 \mathrm{~mm} \times 1 \mathrm{~mm}$. This type of antenna geometry is obtained by cutting four triangles from the corner sides of RSMA and introducing one rectangular slot in the geometry. The structure of OSMARS is shown in figure 5.

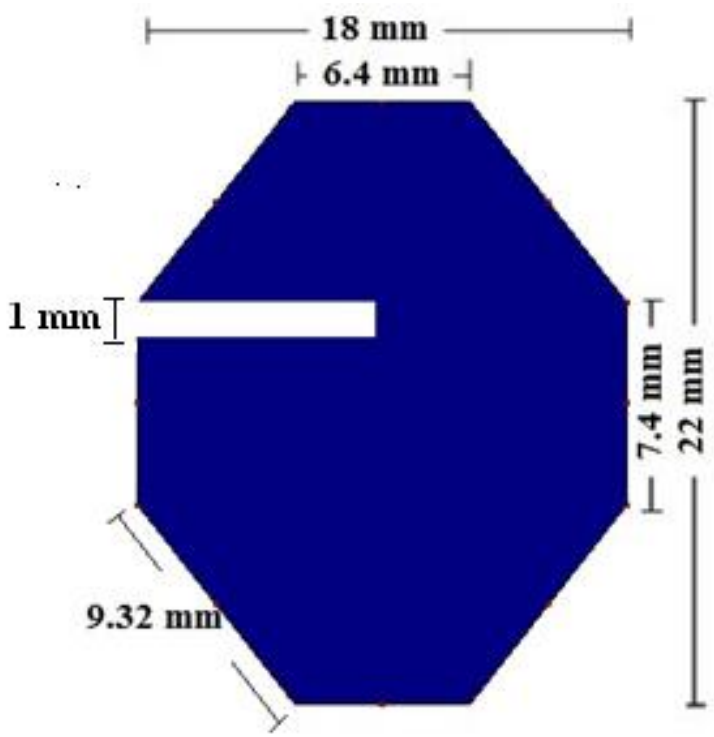

Figure 5: Structure of Octagon Shaped Microstrip Antenna with Rectangular Slot (OSMARS) 
In order to improve the bandwidth stacking principle has been used in which an additional Octal Shaped Microstrip Antenna (OSMA) with the same dimension as OSMARS is placed above the Octagon Shaped Microstrip Antenna with Rectangular Slot (OSMARS). The air gap between OSMA and OSMARS is $0.6 \mathrm{~mm}$. In this stacking configuration, OSMARS is worked as a bottom patch and OSMA is worked as a top patch. Both antennas are electromagnetically coupled. The proposed antenna is identified as Stacked Electromagnetic Coupled Octal Shaped Microstrip Antenna (SECOSMA). The 3D view of the proposed stack configuration of the antennas is shown in the figure 6 .

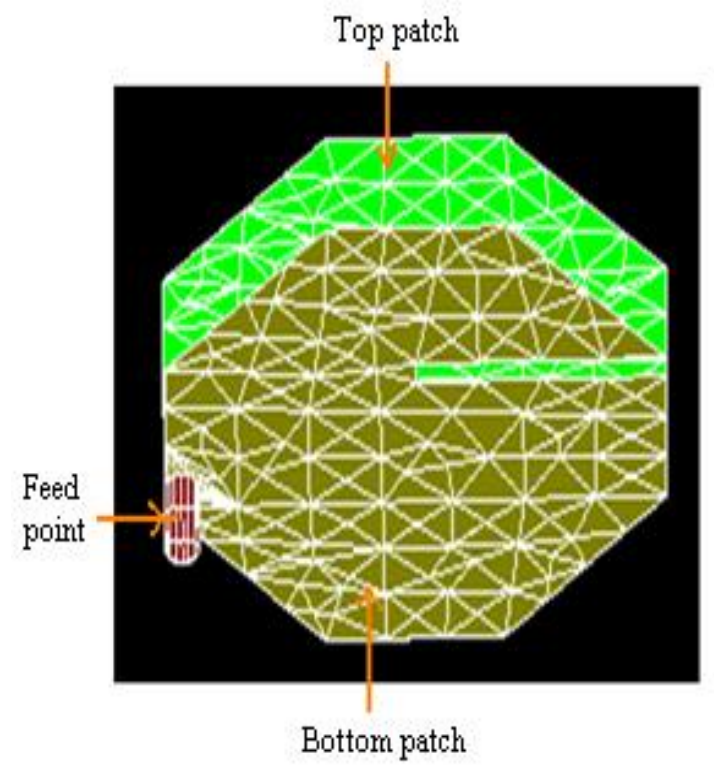

Figure 6: 3-D view of SECOSMA

The figure 7 shows the variation of reflection coefficient with frequency.

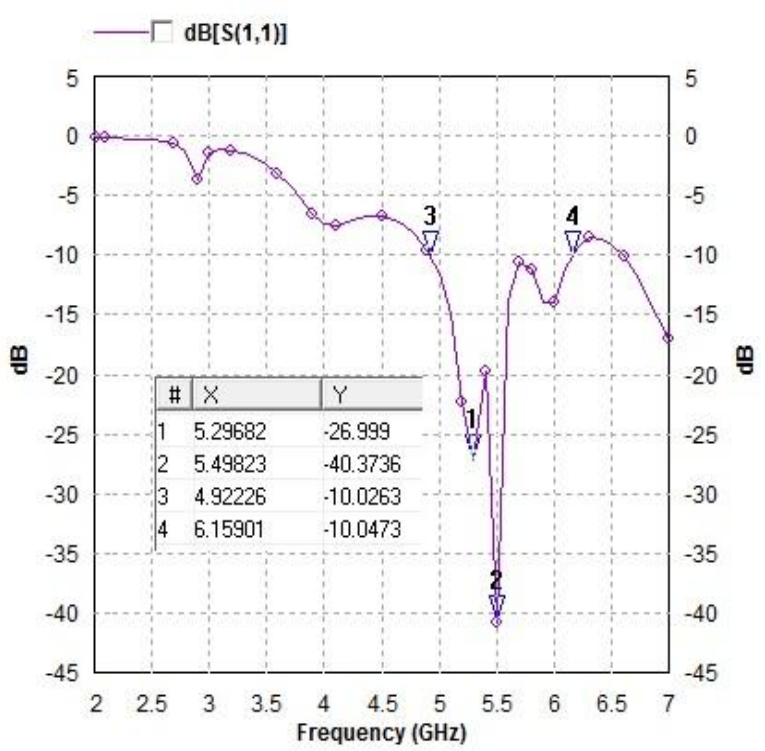

Figure 7: Variation of Reflection Coefficient v/s Resonance Frequency
It shows that the SECOSMA is resonating at resonant frequencies $5.29 \mathrm{GHz}$ and $5.49 \mathrm{GHz}$. The smith chart plot for the proposed antenna is depicted in figure 8 .

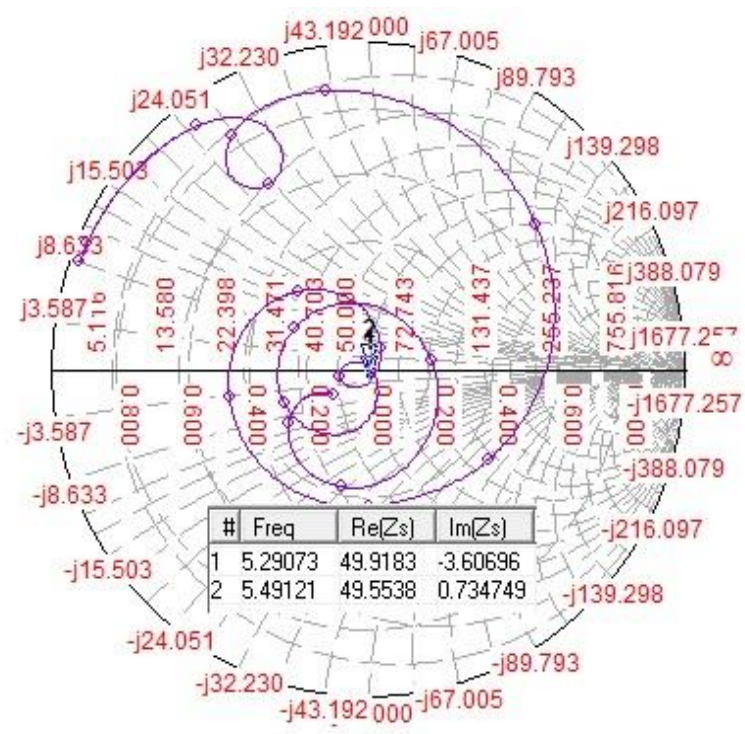

Figure 8: Smith chart plot

The input impedances are (49.91-j3.60) ohm and (49.55+j.73) ohm at two resonant frequencies $5.29 \mathrm{GHz}$ and $5.49 \mathrm{GHz}$ respectively. The value of obtained bandwidth for this antenna is $22.10 \%$. So the performance of SECOSMA is found better than the RSMPA and RSMA since obtained bandwidth is approximately five times higher in comparison with RSMPA and RSMA.

Figure 9 shows the gain curve for the proposed antenna. The simulated gain at frequencies $5.29 \mathrm{GHz}$ and $5.49 \mathrm{GHz}$ are $3.67 \mathrm{dBi}$ and $1.31 \mathrm{dBi}$ respectively.

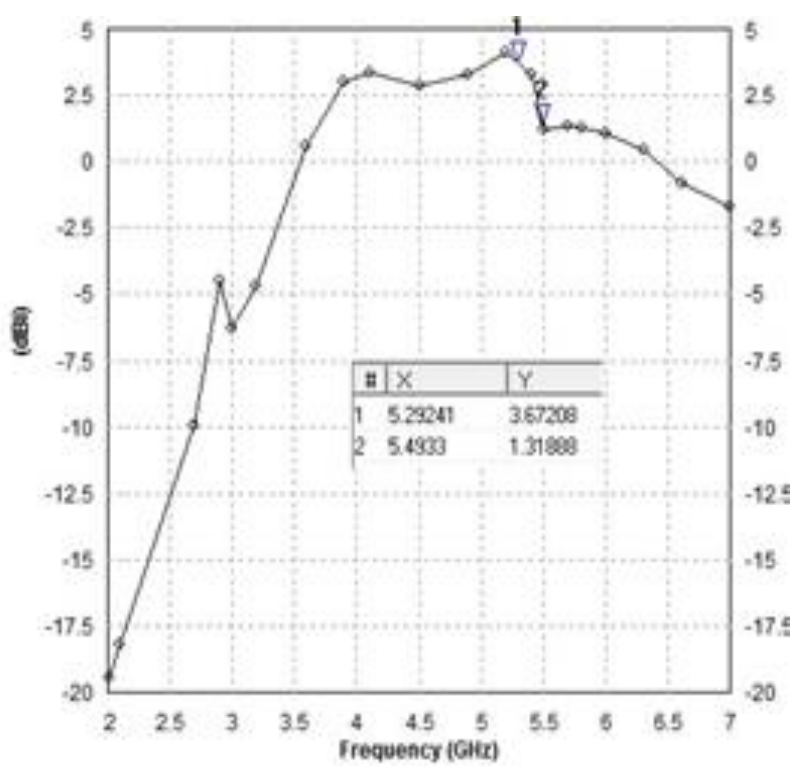

Figure 9: Variation of gain v/s resonance frequencies

The curve between directivity and resonant frequencies is shown in fig. 10 . 


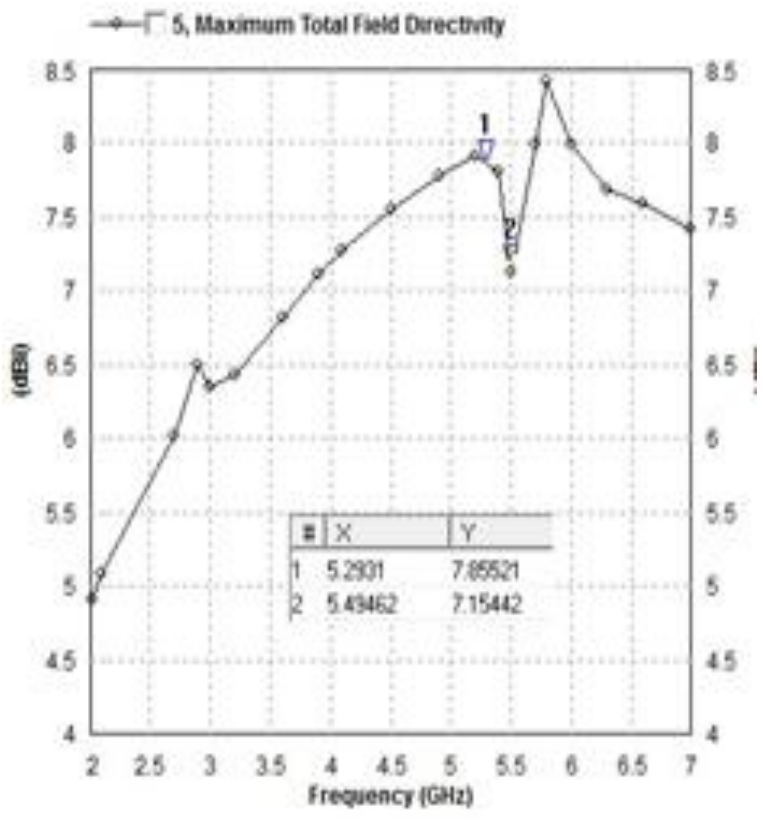

Figure 10: curve between directivity and resonant frequencies

The directivity of this antenna is $7.85 \mathrm{dBi}$ and $7.15 \mathrm{dBi}$ for the resonant frequencies $5.29 \mathrm{GHz}$ and $5.49 \mathrm{GHz}$ respectively. The curve between radiation efficiency and resonant frequencies is shown in figure 11.

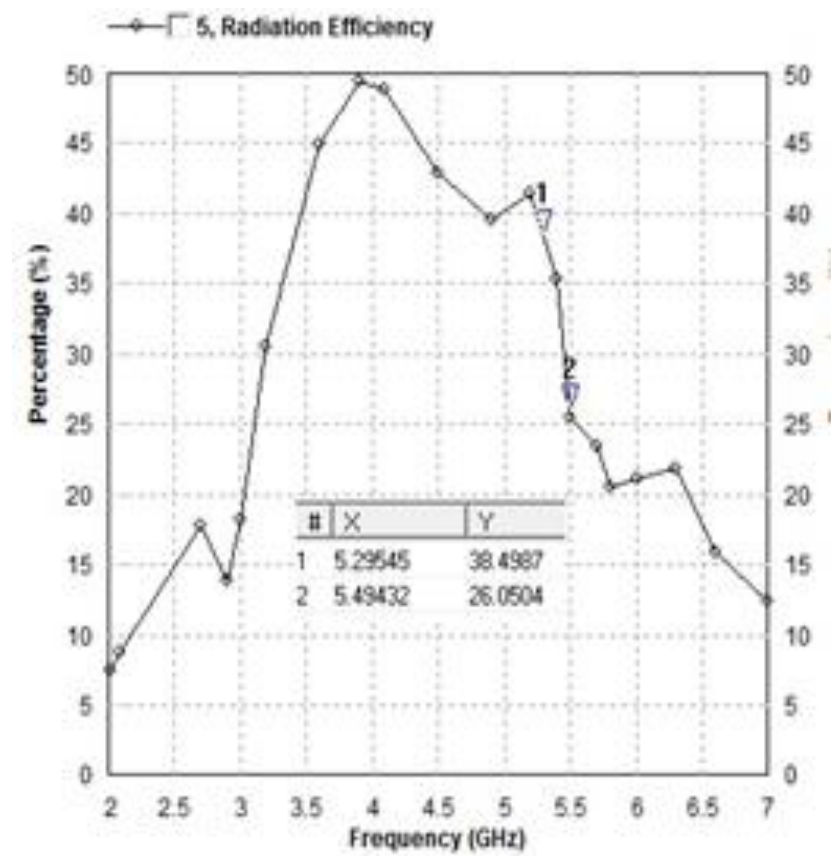

Figure 11: curve between radiation efficiency and resonant frequencies

The radiation efficiency of the antenna is $38.49 \%$ at 5.29 $\mathrm{GHz}$ and $26.05 \%$ at $5.49 \mathrm{GHz}$. The variation of VSWR with the resonance frequencies is shown in figure 12. The values of VSWR at resonance frequencies $5.29 \mathrm{GHz}$ and $5.49 \mathrm{GHz}$ are 1.09 and 1.02 respectively.

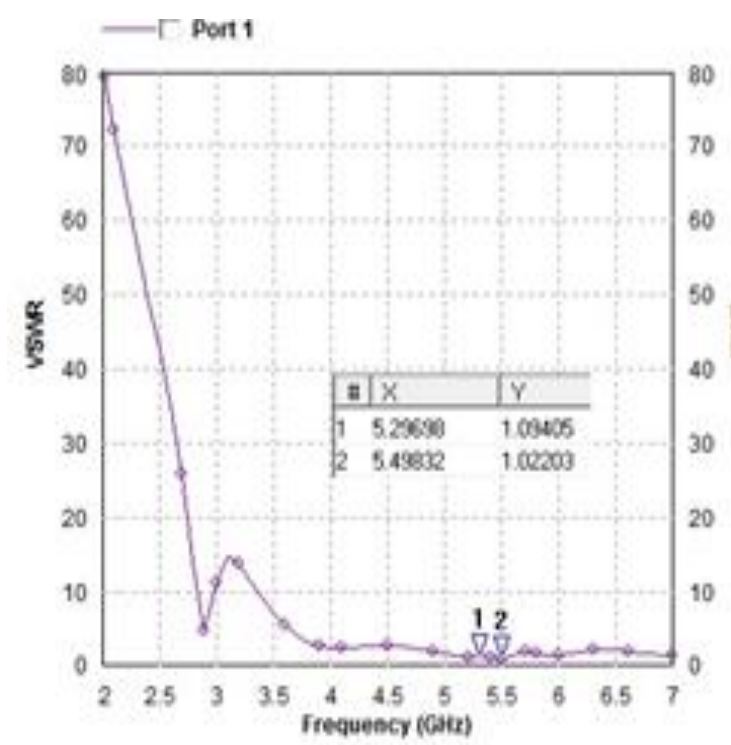

Figure 12: curve between VSWR and resonant frequencies

The radiation patterns at resonant frequencies $5.29 \mathrm{GHz}$ and $5.49 \mathrm{GHz}$ are shown in figure 13 and figure 14 respectively. The direction of maximum radiation is uniform in all direction and normal to the patch as represented in the following figures.

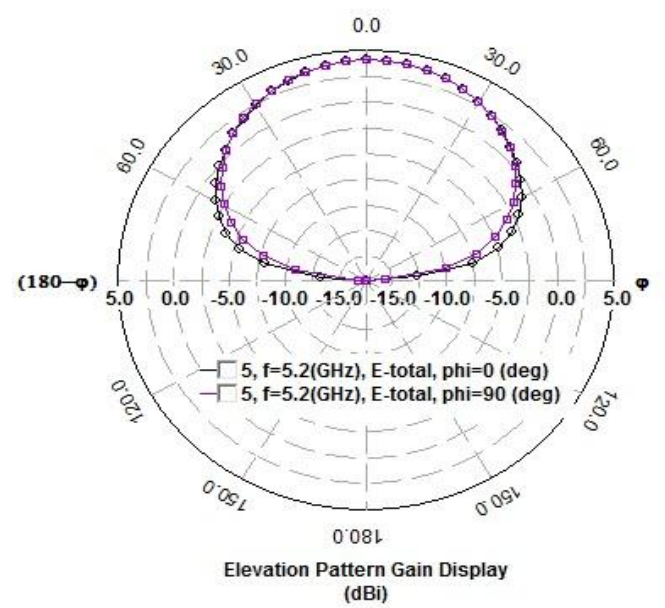

Figure 13: 2D polar Radiation pattern at 5.29GHz

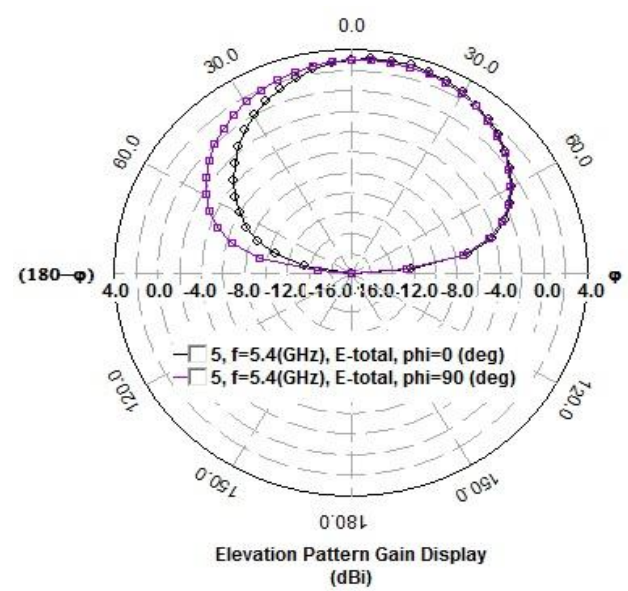

Figure 14: 2D polar Radiation pattern at $5.49 \mathrm{GHz}$ 
Bandwidth is one of the important antenna performance parameter. From the analysis it is realized that impedance bandwidth for SECOSMA is around five times higher in comparison with RSMPA and RSMA. Comparative results are more clearly shown in figure 13 .

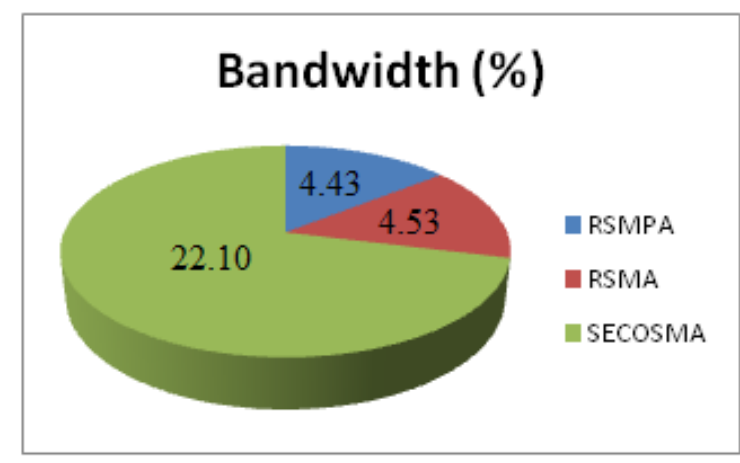

Figure 13: Bandwidth comparison between RSMPA, RSMA and SECOSMA

The graph shown in fig. 14 clearly indicates the comparative results of all three geometries on basis of return loss. It indicates that all geometries have very low return loss as required.

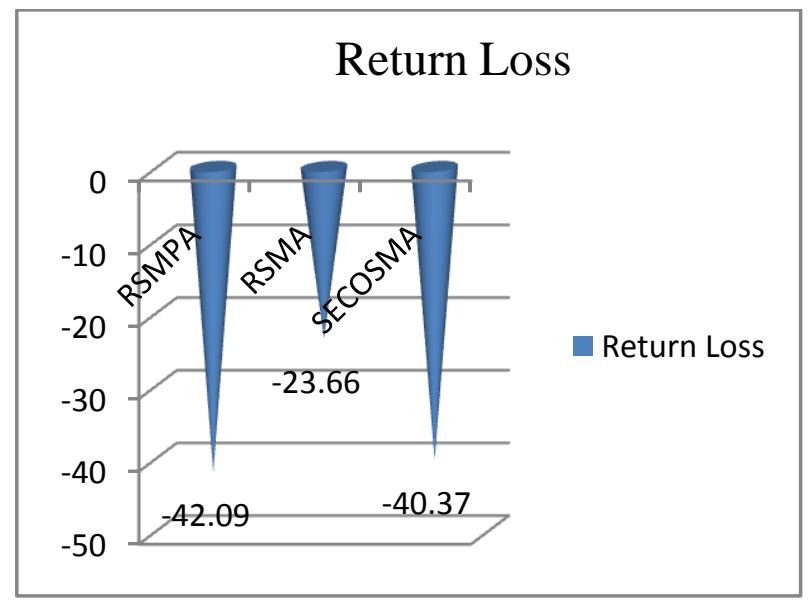

Figure 14: Return loss comparison between RSMPA, RSMA and SECOSMA

\section{CONCLUSION}

The proposed Stacked Electromagnetic Coupled Octagon Shaped Microstrip Antenna (SECOSMA) resonates at two frequencies $5.29 \mathrm{GHz}$ and $5.49 \mathrm{GHz}$. By using this antenna much improved bandwidth of $22.10 \%$ is obtained which is approximately five times higher in comparison with RSMPA and RSMA. The direction of maximum radiation is uniform in all direction and normal to the patch. The gain provided by the proposed antenna is $3.67 \mathrm{dBi}$ which is quite encouraging. The designed antenna exhibits a good impedance matching of about $50 \mathrm{ohm}$. From the analysis of simulated results it can be verified that the proposed antenna is best suitable for WiMax applications. For further improvement in impedance bandwidth, the technique that can be employed is reduction of total area of the radiating patch. The area of the proposed antennas is reduced by making slots on the patch. It can be further reduced by making some fine adjustments in the shape and size of the patch. Therefore, future work on the simulated antennas can be done by doing stacking and making slots on the patch of the antennas which increases the impedance bandwidth of the antennas.

\section{ACKNOWLEDGEMENT}

The authors would like to express their gratitude towards Dr. Rakesh Duggal, Director, Poornima Group of Institutions, Jaipur for his kind cooperation in this research work.

\section{REFERENCES}

[1] Churng-Jou Tsai, Chia-Hsn Lin, Wei-Chih Chen, ChenLin Lu and Jinn-Kwei Guo, Debray, "A CPW-Feed Printed Antenna for Dual-band WLAN operations", IEEE, 2011

[2] I. Balakrishna, M. Suresh kumar and S. Raghavan, "CPW-fed Semi Circle Patch Antenna for $2.4 \mathrm{GHz}$ WLAN Application”, IEEE, 2011.

[3] K. guney, "A simple and accurate expression for the bandwidth of electrically thick rectangular microstrip antennas", Microwave and Optical Technology Letters, Vol.36, No.3, pp. 225-228,2003,Vol. 1 No. 1-2 , JanuaryDecember, 2012.

[4] Kumar G. and Ray K. P., Broadband Microstrip Antenna, Artech House Inc., 2003.

[5] M. Omidi. "Broadband Stacked Microstrip Patch Antenna for L-Band operation: FDTD Modeling", Iranian Journal of Electrical \& Electronic Engineering, Vol. 3, Nos. 643 \& 4, July 2007.

[6] D. Bhardwaj, O.P. Sharma, C.K. Dubey, B.V. Singh, K. Sharma, "Gain and Bandwidth Enhancement of Electromagnetic Gap-Coupled Assembly of Various Patches Forming Rhombus Shaped Microstrip Patch Antenna for C band Application", IJERA, Vol. 4, Issue 5, pp. 55-61, May 2014.

[7] Ch.Radhika, 1D.Ujwala, B.Harish, Ch.Vijaya Sekhar, H.M.Ramesh, "Analysis of the effect of substrate thickness on a rhombus shaped slot triangular Patch Antenna for WLAN application", IJERA, ISNN: 22489622, Vol. 2, Issue 3, pp.2503- 2506, May-Jun-2012.

[8] Tejinder Kaur Gill, Ekambir Sidhu, "Multi Resonant Stacked Microstrip Patch Antenna Designs for IMT, WLAN and Wi Max Applications "International Journal of Advance Research in Computer Engineering and Technology, ISNN: 2218-1323, Vol. 3, Issue 10, October 2014.

[9] Rahul Rana, A.K. Arya, "Dual Stacked Wideband Microstrip Antenna Array for $\mathrm{Ku}$ Band Applications", IJERA, ISNN: 2248-9622, Vol. 4, Issue 6, pp.132-135, June 2014.

[10] Vinod kumar Singh, Zakir Ali, Shahanaz Ayub, "Dual Band Stacked Microstrip Antenna for Wireless Applications" International Journal of Advance Research in Computer Science and Software Engineering, ISNN: 2277 128X, Vol. 2, Issue 2, pp.5-9, February 2014. 